\title{
SMOKING, AWARENESS OF SMOKING-ASSOCIATED HEALTH RISKS, AND KNOWLEDGE OF NATIONAL TOBACCO LEGISLATION IN GAZA, PALESTINE
}

\author{
Reem T. Abu Shomar ${ }^{1}$, Ihab K. Lubbad ${ }^{1}$, Walid El Ansari ${ }^{2}$, Issam A. Al-Khatib ${ }^{3,4}$, Hatem J. Alharazin ${ }^{1}$ \\ ${ }^{1}$ Earth and Human Centre for Research and Studies, Gaza, Palestine \\ ${ }^{2}$ Faculty of Applied Sciences, University of Gloucestershire, Gloucester, United Kingdom \\ ${ }^{3}$ Institute of Community and Public Health, Birzeit University, West Bank, Palestine \\ ${ }^{4}$ Institute of Environmental and Water Studies, Birzeit University, West Bank, Palestine
}

\begin{abstract}
SUMMARY
Aims: To assess university students' extent of smoking, knowledge of smoking health risks, and awareness of existing national anti-smoking laws.

Methods: Self-administered questionnaire was employed across 7 universities (1,104 students, equal proportions of males and females) located in Gaza Strip, Palestine.

Results: About $55 \%$ of participants reported ever smoking, $31 \%$ were current cigarette smokers, and $36 \%$ were 'strictly' (only) narghile (water pipe) smokers. Mean age of smoking initiation was $17 \pm 3.15$ years. Smokers had less knowledge of smoking associated health risks than nonsmokers. Students' knowledge of existing anti-smoking laws was generally low (11.3-25.5\%), and significantly more smokers had knowledge about existing laws (ban of advertisement of smoking, ban of smoking in public places, and ban of selling cigarettes to minors) than non-smokers. About $81 \%$ of current smokers tried to quit smoking at least once during their life, $53 \%$ felt ready to quit smoking if cessation assistance was provided, $17 \%$ were not ready to quit, and $30 \%$ were reluctant/felt unsure if they were ready to quit. Most students $(94.3 \%)$ reported that there were no smoking cessation centres in Palestine, or did not know if such centres existed. Males were associated with almost all categories of smoking (e.g. smoking both cigarettes and narghile, or smoking narghile only).

Conclusions: There is a lack of knowledge about the existing national anti-smoking legislation among university students in Gaza, Palestine. Smoking cessation centres also seem non-existent in Gaza. Multi-level interventions and actions are required by policy makers, educators and non-governmental agencies to prevent smoking among university students in Gaza, and to educate them on tobacco cessation counselling, on the dangers of tobacco use, and about effective stress management strategies to help them to cope with stressors. Smoking cessation interventions are required to address both cigarette and narghile use. Efforts need to be invested in ensuring compliance with legislation and for follow-up activities to enforce the anti-smoking laws through coordinated actions across ministries and departments.
\end{abstract}

Key words: smoking, university, students, narghile, water pipe, anti-smoking laws

Address for correspondence: W. El Ansari, Faculty ofApplied Sciences, University of Gloucestershire, Oxstalls Campus, Oxstalls Lane, Gloucester GL2 9HW, United Kingdom. E-mail: walidansari@glos.ac.uk

\section{INTRODUCTION}

Tobacco use is a risk factor shared by four major non-communicable conditions, it is an important cause of preventable death and without urgent actions to alleviate such burden, one billion people will die from tobacco in the 21 st century (1). In addition, passive smoking (second-hand smoke) causes disease, disability, and death in people who do not smoke (2). Tobacco smoking and passive smoking are global public health challenges.

Tobacco use and the treatment/management of tobacco-related diseases incur financial burdens, particularly for low-income countries with already stretched health budgets. Deaths attributable to cigarette smoking are expected to double in developing countries, as they are now targeted by the tobacco industry (3). Many college students start smoking (4), being easy targets for the tobacco industry and young people are bombarded with protobacco messages and sometimes offered free cigarettes. Such actions violate the claimed responsibility of the tobacco industry for protecting young people from smoking (5).
Tobacco use is risky behaviour among youth that extends into adulthood (6). Quitting smoking is beneficial to health at any age, and smokers who quit before 35 years of age have mortality rates similar to those who never smoked (7). The WHO Framework Convention on Tobacco Control (WHO FCTC) provided basis for countries to implement/manage tobacco control programmes, and the MPOWER package comprises multiple evidence-based tobacco control measures : offering help/assistance to quit tobacco use (smoking cessation services); warning about dangers of tobacco (provision of knowledge/information); and enforcing bans on tobacco advertising, promotion and sponsorship (law enforcement) (8).

Some studies of smoking, its health risks and correlates, associated knowledge and behaviour, and anti-tobacco legislation have been implemented among university students in the Eastern Mediterranean Region (EMR), although scant research has been undertaken in Palestine. Across EMR, university students' smoking is alarming, despite that findings are difficult to compare due to methodological issues (e.g. variations in recall periods). Studies on smoking of EMR students included Lebanon, Turkey, 
Iran, Syria, Jordan, Kuwait, and Saudi Arabia (9-18) and reported higher smoking prevalence. In contrast, other EMR studies found lower smoking prevalence in Egypt and Saudi Arabia $(19,20)$ Likewise, students' views about quitting smoking have been examined in some EMR countries e.g. Turkey and Egypt (11, 19). Again, very little research has been conducted in Palestine.

Smoking among young adults adversely affects their health, and understanding the factors associated with their smoking helps to create effective interventions for prevention of smoking, and for quitting (cessation). Therefore, we assessed many variables (16): demographic and smoking related variables (gender, initiation age, reasons for smoking, having a smoking family member, attitudes and beliefs, sources of and finances to purchase tobacco, smoking and passive smoking related health risks, prevention); cessation variables (smoking cessation/quit attempts and availability of cessation services); legislation and policy variables (anti-smoking laws), and religion/religious practices $(9,12,18,21)$. We included cigarette smoking and narghile smoking (aka shisha, hookah, narghile, water pipe) as both are prevalent in EMR, and included health and religious aspects as both are important motives for not smoking, quitting or attempting to quit (21).

Given the scarce literature on university students' smoking in EMR, very few studies have been conducted in Palestine, despite that university students are at increased risk for future smoking compared with same-age peers not attending college $(22,23)$. Evidence of students' smoking behaviour in Palestine is lacking. Whereas studies have been undertaken among adolescents in Palestine, less data has been published in international and academic journals or exists nationally as government documents to guide prevention/intervention strategies among university students in Palestine (24). Given this scarcity, and the difficulties of accessing universities/educational institutes within Palestine for research, these young adults are hard-to-reach. Such information lack raises concerns, as the scant research in Palestine found that $35 \%$ of university students were cigarette or water pipe smokers (22). The Palestinian no-smoking legislation was passed in 2005 $(25,26)$, but 9 years later, "Information about the rate of smoking and factors associated with initiating/maintaining the behaviour is scarce in Palestine" (22). The current study is an attempt to bridge these knowledge gaps.

This cross-sectional study (2012-2013) surveyed a representative sample of students across 7 universities in Gaza, Palestine. The study assessed students' prevalence of smoking, awareness of smoking and passive smoking associated health risks, actions towards prevention of smoking, views on quitting, and knowledge of existing national anti-smoking legislation (laws). We compared smokers and non-smokers across these variables, and assessed the correlates of smoking. The specific objectives were to:

- describe students' smoking profile, and a range of smoking related variables (e.g., age of smoking initiation, reasons for smoking, sources of and finances to purchase tobacco);

- assess students' awareness of smoking associated health risks, actions to prevent smoking health risks, and views on quitting;

- assess students' knowledge of national anti-smoking legislation and laws in Palestine and the position of Islam on smoking;

- compare smokers' and non-smokers' knowledge of smoking related health risks, actions towards prevention of smoking, national anti-smoking legislation (laws), and position of Islam on smoking;
- assess the variables associated with smoking among Palestinian university students.

\section{Setting: Gaza Strip, Palestine}

Within the Palestinian Territory, $\approx 23 \%$ of those $>18$ years old were smokers (27\% in West Bank; $15 \%$ in Gaza Strip) (27). Youth constitutes one third of the Palestinian society, where the sex ratio among youth comprises nearly equal males and females, and about three out of every 100 young persons suffer from $\geq 1$ chronic disease (28). For Palestinians, the monthly average expenditure on tobacco and cigarettes exceeded the expenditure on education (29). The Palestinian legislation (no-smoking laws), passed in 2005, banned tobacco advertising/promotion, smoking in public places, and selling cigarettes to minors (individuals $<18$ years). However, these laws need to be enforced and there seems no existing system to enforce the legislation (compliance with the laws or implementation of non-compliance penalties) $(25,26)$. This is despite that the Palestinian national policy and strategic plan for non-communicable diseases prevention/management incorporates "strengthening the enforcement of the existing antismoking law and implementation of measures to reduce tobacco use" as a priority objective (30). Hence, a working group was established to support the work of the inter-sectoral committee to develop a national action plan against tobacco (30).

\section{MATERIALS AND METHODS}

\section{Sample and Procedures}

Students from 7 universities in Gaza, Palestine participated in this study (May 2013) (Table 1). These universities provided ethical approval and were selected because they were the largest universities in Gaza. Private, public and governmental universities were included; and students across most of the scientific disciplines taught at the selected Palestinian universities participated. Participants had to be $\geq 18$ years old, enrolled as undergraduate or graduate students at one of the 7 universities and willing to partake in the survey. A self-administered anonymous questionnaire was distributed to a representative sample of students $(1,104$ participants), with a letter indicating the study objectives, confidentiality and voluntary nature of participation. No incentives were provided. Based on the number of returned questionnaires, the response rate was $\approx 96 \%$. A total of 44 questionnaires had missing information on smoking and were not included in the current analysis.

\section{Measures}

Participants contributed socio-demographic data, history of cigarette and water pipe tobacco use, knowledge about smoking and second-hand smoking (SHS) health risks, anti-smoking legislations, and availability of quitting centres. For current smokers, additional items included: age of smoking initiation, number of cigarettes smoked/day, reason/s for initiation of smoking, source of money for smoking, and intent to quit if quitting assistance was provided. Questions used were from published questionnaires $(14,31-33)$ : 
- Smoking (cigarettes and narghile) (4 items):

Ever smoking: "Have you ever tried smoking cigarettes (even one cigarette)?" (Response options: Yes/No);

Current smoking: "Currently, do you smoke cigarettes?" (Regularly, Occasionally, Never);

Number of cigarettes smoked per day: "How many cigarettes do you smoke a day?";

Narghile smoking: Do you smoke narghile? (Yes/No).

- Age of initiation, reasons for smoking and family smoking (4 items):

Age of smoking initiation: "At what age did you start smoking?"; Reasons for initiation of smoking: "Why did you start smoking?" (Response: Peers' pressure, Seeking more attractive appearance, Stress release, Availability of extra money, Others - specify);

Family smoking: "Does anyone in your family smoke?" (First degree relative e.g., father, mother, partner, brother, sister, Relatives other than first degree, Nobody);

Association with smokers: "Do you accept that your first degree relative is/would be a smoker?" (Yes, No, No opinion).

- Sources of and finances to purchase tobacco (2 items):

Source of cigarettes: "The source of the cigarettes you smoke is:" (I buy it from the store, I get it from my friends, I get it from a smoker relative, Others - please indicate);

Money to buy cigarettes: "How do you get money to buy cigarettes?" (Response: My pocket money, I work to collect money, From friends, Other - please indicate).

- Smoking and passive smoking associated health risks and prevention (5 items):

Smoking associated health risks (2 items): "Do you believe that smoking causes harm to your health?" (Response: Yes - please indicate one health problem, No, Don't know). In the second item, students were asked: "Do you believe that smoking narghile causes harm to your health?" (Yes, No, Don't know); Passive smoking associated health risks (2 items): "Passive smoking or 'second hand smoking' means that": (The affected person is a non-smoker, The affected person is the smoker, The smoker acts in a passive way, Others). The second item was: "Do you believe that you will be harmed if somebody smokes near you?" (Yes, No, Don't know);

Prevention of passive smoking: "Have you tried to prevent smoking near you?" (Yes - always, Yes - sometimes, No).
- Smoking cessation (Quitting) attempts and availability of services (4 items):

Quit attempt/s (self and others) (2 items): "Have you ever tried to quit smoking?" (Response: Yes - how many attempts?, No). In the second question, students were asked: "Have you tried to advice or help somebody to quit smoking?" (Yes - always, Yes - sometimes, No);

Smoking cessation services and availability (2 items): "Are you ready to quit smoking if cessation assistance was provided?" (Yes, No, Not sure). In second item, participants were asked: "Is there any smoking quitting Centre in your country?" (Yes, No, Don't know).

- Legislation, anti-smoking laws and position of Islam on smoking (4 items):

Ban on Tobacco advertising: "Is there a Palestinian law that bans tobacco advertising and promotion?" (Yes, No, Don't know); Ban of smoking in public places: "Is there a Palestinian law that bans smoking in public places?" (Yes, No, Don't know); Ban of Tobacco sales to minors: "Is there a Palestinian law that forbids the selling of cigarettes to those $<18$ years old?" (Yes, No, Don't know);

Position of Islam on smoking: "Smoking in Islam is" (Accepted, Prohibited, Don't know).

\section{Data Analysis}

SPSS version 20 was employed for the analysis $(p<0.05)$. Descriptive analysis of smoking and related variables was conducted (current cigarette smoking status, gender, awareness regarding cigarettes and/ or narghile smoking and associated risks, national anti-smoking laws, position of Islam on smoking). Chi square tests examined the relationship between (dependent and independent) categorical variables. Logistic regression measured the association between the independent variables and students' smoking status (correlates of different types of smoking and their combinations). For the regression, first, for each smoking category under examination, all the variables were entered in the regression model. Then we removed the variables that were not statistically significant, and ran the model again. Hence, only the variables that were statistically significant are presented in the regression Table 6 . However, for the smoking category 'cigarettes only', the number of participants was small $(n=40)$.

Table 1. Characteristics of participating universities in Gaza Strip, Palestine

\begin{tabular}{|c|c|c|c|c|}
\hline University & $\begin{array}{l}\text { Participants } \\
(\mathrm{N}=1060)\end{array}$ & $\begin{array}{c}\text { Age } \\
\text { M(SD) }\end{array}$ & $\begin{array}{c}\text { Female } \\
\mathrm{N}=530(\%)\end{array}$ & $\begin{array}{c}\text { Male } \\
\mathrm{N}=530(\%)\end{array}$ \\
\hline \multicolumn{5}{|l|}{ Governmental (Ministry of Higher Education) } \\
\hline Al Aqsa University - Gaza & 80 & $24(3.3)$ & $40(50.0)$ & $40(50.0)$ \\
\hline \multicolumn{5}{|l|}{ Private } \\
\hline Palestine University & 300 & $22(2.7)$ & $130(43.3)$ & $170(56.7)$ \\
\hline Gaza University & 80 & $22(2.6)$ & $50(62.5)$ & $30(37.5)$ \\
\hline \multicolumn{5}{|l|}{ Public (Board of Trustees) } \\
\hline Al Quds Open University & 220 & $22(2.2)$ & $130(59.1)$ & $90(40.9)$ \\
\hline Al-Azhar University & 210 & $22(2.4)$ & $70(33.3)$ & $140(66.7)$ \\
\hline Islamic University of Gaza & 120 & $22(2.8)$ & $70(58.3)$ & $50(41.7)$ \\
\hline University College of Applied Sciences & 50 & $21(2.5)$ & $40(80.0)$ & $10(20.0)$ \\
\hline
\end{tabular}




\section{RESULTS}

\section{General Characteristics of the Sample}

Of the 1,104 students provided with the questionnaire, we received data from 1,060 (96\%) individuals. There were equal numbers of males and females (Mean age $22 \pm 2.6$ years) (Table 1). Participants represented many disciplines, categorized broadly into literary faculties $(\mathrm{n}=650,61.3 \%$ of sample) and scientific faculties $(n=408,38.5 \%)$. These included Education $(n=308$, $29.1 \%$ of sample), Commerce/Business ( $n=209,19.7 \%$ ), Information Technology/Computing $(\mathrm{n}=173,16.3 \%)$, Engineering $(\mathrm{n}=83,7.8 \%)$, Health Sciences $(\mathrm{n}=33,3.1 \%)$, Media $(\mathrm{n}=45$, $4.2 \%)$, Medicine $(\mathrm{n}=39,3.7 \%)$, Law $(\mathrm{n}=34,3.2 \%)$, Science $(\mathrm{n}=32,3 \%)$, Arts $(\mathrm{n}=31,2.9 \%)$, Agriculture $(\mathrm{n}=19,1.8 \%)$, Pharmacy $(n=16,1.5 \%)$, Communications $(n=14,1.3 \%)$, Nursing $(\mathrm{n}=13,1.2 \%)$, and Religious studies $(\mathrm{n}=9,0.8 \%)$.

\section{Students' Smoking Profile}

About $54.7 \%$ reported ever smoking cigarettes ( $\geq 1$ cigarette during their life); and $31.1 \%$ were current cigarette smokers. Of the current cigarette smokers $(n=330)$, males comprised $87.9 \%$ (n $=290)$ and females $12.1 \%(n=40)$. Figure 1 depicts respondents as cigarette and/or narghile smokers or non-smokers. About $21 \%$ of the sample smoked cigarettes regularly, of which $86 \%$ also smoked narghile. In addition, $10 \%$ of respondents smoked cigarettes occasionally, of which $91 \%$ also smoked narghile. About $68.9 \%$ of the sample did not smoke cigarettes and of those, about $36 \%$ were 'strictly' (only) narghile smokers. Hence, we had current smokers (cigarettes or narghile or both) $(\mathrm{n}=590)$; narghile only (no cigarettes) $(n=260)$; cigarettes only (no narghile) $(n=$ $40)$; and non-smokers $(\mathrm{n}=470)$.

For cigarette smokers with available data $(n=590), 74.1 \%$ initiated smoking cigarettes at $<18$ years of age, while $25.9 \%$ started smoking at $\leq 15$ years. The mean initiation age was 17 years \pm SD 3.15, and the average number of cigarettes smoked daily was 14 cigarettes (range 1-33). Current smokers' main reasons for smoking were peer pressure $(32.3 \%)$, stress release (29\%), seeking more attractive appearance $(6.5 \%)$, and availability of extra money (6.5\%). As for family smoking, 59.3\% of current smokers had first degree relative/s who smoked, and $33.9 \%$ had second degree relative/s who smoked; whereas non

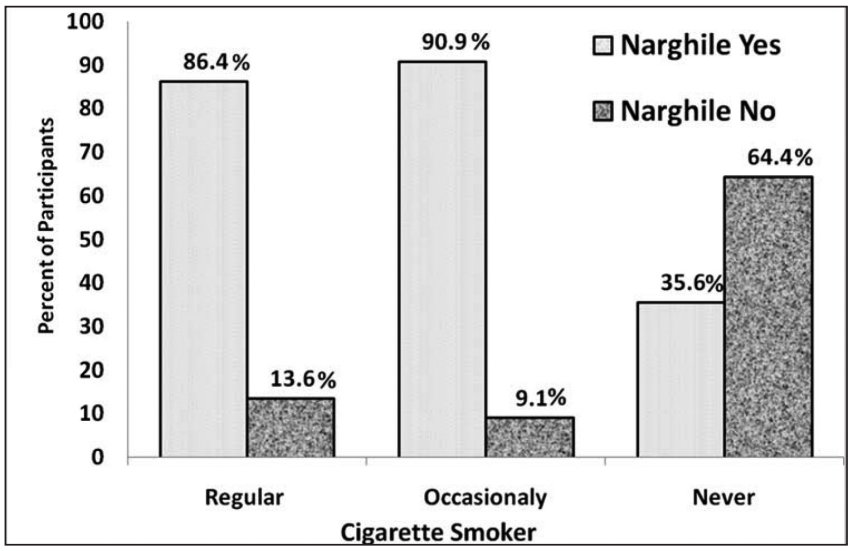

Fig. 1. Cigarettes and Narghile smoking among students in Palestine.

smokers with first and second degree smoker relative/s were $66 \%$ and $31.9 \%$, respectively. As for acceptance of smoking in their families, $61 \%$ of smokers and $85.1 \%$ of non smokers did not accept that their first degree relative would be a smoker. About $90 \%$ of current smokers bought their cigarettes from stores; the remaining got their cigarettes from friends/other sources. Nearly $\approx 65 \%$ used their pocket money to purchase cigarettes, $25.8 \%$ worked to have the required money, and $9.7 \%$ used 'other' sources to get the money needed to purchase cigarettes.

\section{Awareness of Smoking and Passive Smoking Health Risks and Actions towards Prevention}

About $88.7 \%$ of students were aware that smoking cigarettes is harmful to both the smokers and the non-smokers who inhale the smoke (Table 2), and $86.8 \%$ believed that smoking narghile is also dangerous to health. The most reported health problems were cancer, respiratory diseases, and heart and vascular diseases. In terms of prevention of passive smoking and advice to quit, 33\% of students tried and $33 \%$ sometimes tried to prevent smokers from smoking near them, while $34 \%$ never did. About $76.4 \%$ of the sample had tried to advice/help somebody to quit smoking (23.6\% never tried this). Nearly $94.3 \%$ reported that there were no smoking cessation centres or that they did not know whether such centres existed, while $5.7 \%$ believed that there actually were smoking cessation centres in Palestine.

Table 2. Awareness of smoking and passive smoking associated health risks and prevention among university students in Gaza Strip, Palestine

\begin{tabular}{|c|c|c|}
\hline Variable & Yes $(\%)$ & No/Don't know (\%) \\
\hline Smoking cigarettes is harmful to your health & 88.7 & 11.3 \\
\hline You will be harmed if somebody smokes near you & 83.0 & 17.0 \\
\hline Smoking Narghile causes harm to your health & 86.8 & 13.2 \\
\hline Passive smoking means "The affected person is a non-smoker" & 62.3 & 37.7 \\
\hline Accept that your first degree relative/s would be a smoker & 17.9 & 82.1 \\
\hline Tried to prevent smoking near you & 66.0 & 34.0 \\
\hline Tried to advice or help somebody to quit smoking & 76.4 & 23.6 \\
\hline Is there any smoking quitting centre/s in your country? & 5.7 & 94.3 \\
\hline
\end{tabular}


As for quitting, $\approx 81 \%$ of current smokers had tried to quit smoking at least once during their life, $53 \%$ had readiness to quit smoking if cessation assistance was provided, $17 \%$ were not ready to quit, and $30 \%$ were reluctant/felt unsure about readiness to quit (Table 3).
Knowledge of National Anti-smoking Legislation, and Position of Islam on Smoking

Knowledge of existing Palestinian anti-smoking laws (legislation) was low (Table 4). Only $\approx 11 \%$ knew about the Palestinian law that banned tobacco advertisement/promotion, $\approx 14 \%$ knew

Table 3. Quitting among university students in Gaza Strip, Palestine*

\begin{tabular}{|l|c|c|}
\hline Variable & Yes (\%) & No/Not sure (\%) \\
\hline Ever tried to quit smoking & 80.6 & $19.4^{* *}$ \\
\hline Ready to quit smoking if cessation assistance was provided & 53.3 & 46.7 \\
\hline
\end{tabular}

* Analysis undertaken only for smokers; ${ }^{*}$ No only (Response options: Yes/No)

Table 4. Students' knowledge of national anti-smoking legislation in Palestine, and position of Islam on smoking

\begin{tabular}{|l|c|c|}
\hline Variable & Yes (\%) & No/Don't know (\%) \\
\hline Palestinian law that bans tobacco advertising and promotion & 11.3 & 88.7 \\
\hline Palestinian law that forbids selling cigarettes to those < 18 years of age & 14.2 & 85.8 \\
\hline Palestinian law that bans smoking in public places & 25.5 & 74.5 \\
\hline Smoking is prohibited in Islam & 60.4 & 39.6 \\
\hline
\end{tabular}

Table 5. Current smoking status among Palestinian university students by selected variables

\begin{tabular}{|c|c|c|c|c|}
\hline \multirow{2}{*}{ Variable } & \multicolumn{2}{|c|}{ Current smoker $(\%)$} & \multirow{2}{*}{$\mathrm{X}^{2}$} & \multirow{2}{*}{$\mathbf{P}$} \\
\hline & Yes & No & & \\
\hline \multicolumn{5}{|l|}{ Gender } \\
\hline Male & 72.9 & 21.3 & \multirow{2}{*}{278.7} & \multirow{2}{*}{$<0.001$} \\
\hline Female & 27.1 & 78.7 & & \\
\hline \multicolumn{5}{|c|}{ Smoking causes harm to your health } \\
\hline Yes & 83.1 & 95.7 & \multirow{2}{*}{44.7} & \multirow{2}{*}{$<0.001$} \\
\hline No/Don't know & 16.9 & 4.3 & & \\
\hline \multicolumn{5}{|c|}{ Passive smoking causes harm to your health } \\
\hline Yes & 72.9 & 95.7 & \multirow{2}{*}{89.8} & \multirow{2}{*}{$<0.001$} \\
\hline No/Don't know & 27.1 & 4.3 & & \\
\hline \multicolumn{5}{|c|}{ Tried to advice or help somebody to quit smoking } \\
\hline Yes & 64.4 & 91.5 & \multirow{2}{*}{113.7} & \multirow{2}{*}{$<0.001$} \\
\hline No & 35.6 & 8.5 & & \\
\hline \multicolumn{5}{|c|}{ Existence of Palestinian laws that ban: } \\
\hline \multicolumn{5}{|c|}{ Tobacco advertising/promotion } \\
\hline Yes & 11.9 & 10.6 & \multirow{2}{*}{0.4} & \multirow{2}{*}{0.531} \\
\hline No/Don't know & 88.1 & 89.4 & & \\
\hline \multicolumn{5}{|c|}{ Smoking in public places } \\
\hline Yes & 30.5 & 19.1 & \multirow{2}{*}{17.8} & \multirow{2}{*}{$<0.001$} \\
\hline No/Don't know & 69.5 & 80.9 & & \\
\hline \multicolumn{5}{|c|}{ Selling cigarettes to those $<18$ years } \\
\hline Yes & 20.3 & 6.4 & \multirow{2}{*}{41.9} & \multirow{2}{*}{$<0.001$} \\
\hline No/Don't know & 79.7 & 93.6 & & \\
\hline \multicolumn{5}{|c|}{ Is smoking prohibited in Islam? } \\
\hline Yes & 55.9 & 66 & \multirow{2}{*}{10.9} & \multirow{2}{*}{0.001} \\
\hline No/Don't know & 44.1 & 34 & & \\
\hline
\end{tabular}


about the law that banned smoking in public places, and 26\% knew about the law that banned selling cigarettes to minors $(<18$ years). About $60 \%$ reported that Islam prohibits smoking, 34\% did not know what the Islamic position was, and $6 \%$ believed that smoking is accepted in Islam.

\section{Knowledge and Actions: Comparison of Smokers and Non-smokers}

There were statistically significant differences between current smoking status and many variables (Table 5). By gender, there were significantly more male smokers $(72.9 \%)$, and more female nonsmokers $(78.7 \%)$. As for smoking associated health harm, more smokers $(16.9 \%)$ did not recognize the negative health effects compared to non-smokers $(4.3 \%)$. Moreover, significantly more smokers $(27.1 \%)$ were unaware about the health risks of passive smoking (4.3\%), and did not try to advice or help somebody to quit smoking compared to non-smokers. Regarding legislation knowledge, significantly more smokers had knowledge about existing anti-smoking laws than non-smokers. In terms of the position of Islam on smoking, more non-smokers agreed that it was forbidden in Islam.

\section{Variables Associated with Different Types of Smoking and Their Combinations among University Students in Palestine}

Table 6 depicts the correlates of the different types of smoking and their combinations. For the smoking category (cigarettes only), the number of participants was small $(n=40)$.
Males were significantly associated with almost all categories of smoking (except cigarettes only). Compared to non-smokers, smokers of most categories were significantly less likely to report that smoking causes harm to one's health and less likely to try to prevent smoking near them. For most smoking categories, smokers were more likely to accept that their first degree relative is a smoker. As for knowledge of national anti-smoking legislation, a mixed pattern of findings emerged, where some categories of smoking were associated with increased likelihood of such knowledge (e.g. smokers who smoked both cigarettes and narghile were more likely to know of the Palestinian law that bans smoking in public places), or conversely, some categories of smoking were associated with decreased likelihood of such knowledge (e.g. 'strictly' narghile smokers were less likely to know of the Palestinian law that bans tobacco advertising/promotion).

\section{DISCUSSION}

We examined the prevalence of different types of smoking among students at 7 universities in Gaza, Palestine, along with their awareness of smoking health risks and their prevention, and knowledge of existing national anti-smoking legislation. Such information is critical for the development of strategies/ interventions for these students, given that such young adults are at increased risk for future smoking, compared with same-age peers not attending college (23).

For the study's first objective, for current smoking (cigarettes, narghile or both), we had $55.7 \%$ current smoking prevalence ( $72.9 \%$ males, $27.1 \%$ females), higher than Turkey (25\% current

Table 6. Adjusted odds ratios for variables associated with different categories of smoking and their combinations among Palestinian university students*

\begin{tabular}{|c|c|c|c|c|c|c|}
\hline & \multicolumn{2}{|c|}{ Cigarettes and narghile } & \multicolumn{2}{|c|}{ Narghile only } & \multicolumn{2}{|c|}{ Cigarettes only } \\
\hline Participants (n) included in analysis* & \multicolumn{2}{|c|}{250} & \multicolumn{2}{|c|}{140} & \multicolumn{2}{|c|}{40} \\
\hline Variable & $P$ & $\mathrm{OR}(95 \% \mathrm{Cl})$ & $P$ & OR $(95 \% \mathrm{Cl})$ & $P$ & $\mathrm{OR}(95 \% \mathrm{Cl})$ \\
\hline Constant & 0.004 & 3.32 & - & - & $<0.001$ & 0.08 \\
\hline Gender (Male) & $<0.001$ & $\begin{array}{c}41.34 \\
(19.65-86.97)\end{array}$ & $<0.001$ & $\begin{array}{c}11.56 \\
(6.47-20.64)\end{array}$ & - & - \\
\hline Smoking causes harm to your health (Yes) & $<0.001$ & $\begin{array}{c}0.06 \\
(0.02-0.16)\end{array}$ & $<0.001$ & $\begin{array}{c}0.10 \\
(0.04-0.27) \\
\end{array}$ & - & - \\
\hline Tried to prevent smoking near you (Yes) & $<0.001$ & $\begin{array}{c}0.08 \\
(0.04-0.14)\end{array}$ & $<0.001$ & $\begin{array}{c}0.24 \\
(0.13-0.45)\end{array}$ & - & - \\
\hline Accept that your first degree relative is smoker (Yes) & - & - & 0.004 & $\begin{array}{c}2.23 \\
(1.29-3.86)\end{array}$ & 0.013 & $\begin{array}{c}2.67 \\
(1.23-5.78)\end{array}$ \\
\hline \multicolumn{7}{|l|}{ Existence of Palestinian laws that ban: } \\
\hline Smoking in public places (Yes) & 0.005 & $\begin{array}{c}2.23 \\
(1.27-3.92)\end{array}$ & - & - & - & - \\
\hline Tobacco advertising/promotion (Yes) & - & - & 0.020 & $\begin{array}{c}0.37 \\
(0.16-0.85)\end{array}$ & - & - \\
\hline Selling cigarettes to minors (Yes) & - & - & - & - & - & - \\
\hline Nagelkerke $\mathrm{R}^{2}$ & 0.70 & & 0.51 & & 0.03 & \\
\hline Homer \& Lemeshow test (p-value) & $<0.001$ & & $<0.001$ & & 0.999 & \\
\hline
\end{tabular}

$\mathrm{OR}=$ Odds Ratio; $\mathrm{Cl}=$ Confidence interval; $-=$ non significant; * number of participants included in each analysis is usually less than number of participants in the dataset for each category of the three categories of smoking as those reporting 'don't know' to the legislation questions were excluded from the analysis. 
smokers), Jordan (29\% smoked cigarettes in past 30 days), Syria (27\% smoking prevalence), Iran (21.5\% smoked during the past 30 days), and Egypt ( $9 \%$ smoked during the 3 months before the survey) $(11,12,16,19,34)$. About $54.7 \%$ of our sample ever smoked cigarettes ( $\geq 1$ cigarette during their life), similar to Jordan (57\% cigarette ever smoking rate) (16). However, our ever smoking prevalence was higher than in Iran (13).

As for gender, we had much more current smoker males (72.9\%) than females $(27.1 \%)$, which is expected in a culture were female smokers are stigmatized. Our gender-specific current smoker prevalence was higher than in Syria (31\% male and 7\% female current cigarette smokers) (14), and our $12.1 \%$ female current smokers was more than the $4.3 \%$ current smoking rate (cigarettes) in Saudi Arabia (20). In agreement with our genderspecific findings, in Syria, male students had 3 times higher risk of smoking than females (15); in Turkey, smoking ratios of males were higher than females (10); and in Iran, females were less likely to smoke/use water pipe (12). Our findings support the assumption that the lower rate of female smoking is due to cultural reason (smoking is considered inappropriate behaviour for women) (21). Arab countries show significantly higher rates of cigarette smoking among males, due to the social stigma of women's smoking (35). In Pakistan, 87\% of students reported that reasons for women not smoking included that it was 'frowned upon' (36). Gender differences could be culture specific, as the ratio of smoking is high among men in Eastern societies, but high among women in western societies when compared to eastern societies $(37,38)$. Female smoking is increasing in developing countries, where socio-cultural norms are weakening, rendering female smoking more acceptable, together with greater female autonomy, social freedom, changes in women's roles, and rise in spending power among females making cigarettes affordable (15). Certainly, some females who smoked may not have reported their habit due to stigma (21).

As for the age of cigarette smoking initiation, the mean age of smoking initiation was $\approx 17$ years ( $26 \%$ of students started smoking at $\leq 15$ years of age). This is in consonance with Saudi Arabia results (64\% started smoking at $16-18$ years) (18), and mean smoking initiation age was $15.8 \pm 3.3$ years (21). In Turkey, first smoking age was $15.4 \pm 4.1$ years (10), and in Iran, $10 \%$ of students initiated cigarette smoking at 16-17 years, with the rate of initiation increasing to $30 \%$ by the age of twenty and $50 \%$ by the age of twenty-four (12). Others reported an $18 \pm 2.6$ years average age for smoking initiation (11). Such young initiation age in our sample coincides with the end of high school, where students are exposed to the stress of secondary school certificate examinations. Hence, early intervention at secondary education could reduce the smoking prevalence among youth. In addition, educational/recreational sessions on stress and time management could help students to pass their secondary education without smoking. In the USA (first-year college women, M age 18.1 years), pre-college hookah use predicted initiating/resuming cigarette use (39). Our sample's initiation age also coincides with the mean age of entry to university, which is a period of change with less parental control and the stress of achieving academic success might lead to unhealthy habits. The smoking initiation process from birth to young adulthood seems nonhomogeneous, with distinct subgroups whose risk of smoking onset is linked to specific stages in the life course (e.g. the Teenage Risk Group that initiated smoking by the age of 18 years) (40). However, from a prevention perspective, the university years are a critical transition period in cigarette use and an opportunity window, as these young adults' smoking might be more 'changeable/mutable' compared to older, more 'hardened' smokers (4).

In terms of reasons for smoking initiation, our current cigarettes smokers reported peer pressure (32.3\%), stress release (29\%), seeking more attractive appearance $(6.5 \%)$, and the availability of extra money (6.5\%). Similarly, in Saudi Arabia, students' motives for smoking included imitation of others, leisure or relief of pressure (21). Young people start smoking to enhance their social status, relieve anxiety, for stimulation, out of curiosity, or peer pressure (41). Indeed, many smokers started smoking for entertainment purposes (20), and curiosity was significant for initiation (42). Our sample cited stress release as reason for smoking initiation, suggesting that students need knowledge about stress management strategies to help them cope with stressors and not depend on smoking for stress relief (20).

As for family smoking, about $59.3 \%$ and $66 \%$ of our current smokers and non-smokers, respectively, had first degree relative/s who smoked. Whilst in Turkey smoking of a family member did not affect the students' smoking status (10), in Saudi Arabia, 56\% of smokers were inspired to smoke by their parents/other family member/s (20). Likewise, in Jordan, students living on their own had lower odds of smoking water pipe than those living with their parents, where in EMR, water pipe smoking is commonly shared within a family (14).

As for sources of and finances to purchase tobacco, $\approx 65 \%$ of our current cigarette smokers used their pocket money to purchase cigarettes, while $25.8 \%$ work to gain the required money. Financial considerations are critical; in Cyprus, girls' intention to quit was inversely associated with pocket money, and tax increase (and hence cigarette prices) decreased tobacco consumption and tobacco-related morbidity and mortality (43-45). Particularly in Palestine (low-income country), such strategies might be useful, in contrast to high-income countries such as Saudi Arabia, where for university students, financial issues were least important for initiating/quitting, maybe because of the high income per capita and because tobacco is among the least expensive products there (21). Similarly in Turkey, students' income did not influence smoking status perhaps as grants/financial supports received at the university approximate most students to one another despite different family income levels (10).

In terms of our second objective, $83-89 \%$ of our students recognized smoking-related health risks (Table 2). Despite this, further analysis revealed significant differences between smokers and non-smokers, where relatively more non-smokers recognized the negative harms of smoking and passive smoking on health (Table 4). In Turkey, the knowledge about health hazards of passive smoking was lower among smokers than non-smokers (46). Such findings highlight the importance of targeting smokers in awareness campaigns. An additional concern is the tendency towards other tobacco products e.g. narghile that was highlighted across our sample. About $52.7 \%$ of our narghile smokers also smoked cigarettes. Water pipe tobacco smoking prevalence in EMR and worldwide is increasing, where between 1999 and 2007 water pipe use in the Middle East rose 200\% among women and 60\% among men (47-49). In Jordan, female students preferred narghile (50), and in Egypt, $74 \%$ of female water pipe smokers preferred this 
method because they believed it was less harmful than smoking cigarettes (42). Hence there is a need to address this trend in antitobacco intervention measures, as this presents new challenges for health professionals unaccustomed with the practice/health consequences of narghile smoking (51). People perceive water pipe use as more socially acceptable and less harmful than cigarettes, despite contrary evidence (52). Indeed, $48.5 \%$ and $55 \%$ of students in Malaysia viewed shisha as less harmful than cigarettes and less addictive (48). Water pipe-associated health risks include the spread of infectious diseases, e.g. tuberculosis, due to water pipe sharing, or the addition of psychoactive drugs to the tobacco (51). Hence, understanding the reasons/motivations for the rise in narghile use is the key for planning prevention, cessation, and policy interventions. In addition, the co-occurrence of smoking behaviours (cigarettes, water pipe) highlight the need to 'bundle' preventive interventions in order to address both narghile and cigarette use (39). In our sample, $27.4 \%$ smoked both cigarettes and narghile. Introducing health warnings on narghile tobacco products could have public health benefits (53).

As regards to quitting, $81 \%$ of our current cigarette smokers tried to quit smoking at least once during their life, and 53\% expressed readiness to quit if cessation assistance was provided. In Egypt, about one in four university students who smoked attempted to quit (42), and in Lebanon, 38\% of smoker students intended to quit smoking in the future (9). In terms of students' knowledge of the availability of smoking cessation centres in Palestine, $94.3 \%$ reported that there were no smoking cessation centres or they did not know whether such centres existed. Although $53 \%$ of current cigarette smokers expressed readiness to quit smoking if cessation assistance was provided, unfortunately, anecdotal evidence suggests that there are currently no cessation assistance centres in Palestine. In addition, 30\% of our current cigarette smokers were reluctant/felt unsure if they were ready to quit, suggesting a need to establish and equip quitting centres. Conversely, $17 \%$ of current cigarette smokers were unready to quit which provides an indication of tobacco addiction and suggests that these smokers will continue to smoke. Thus designing unconventional interventions for these 'hard' smokers could involve psychological support. Whilst $76.4 \%$ of our sample had tried to advice/help somebody to quit smoking, interestingly, among medical students in Lebanon, only a minority received formal training in treatment approaches for tobacco dependence (9). In Greece, health professions students' training on cessation counselling was low, with need to educate the students on tobacco cessation counselling, dangers of tobacco use, and the positive influence they can play to affect their patients' smoking habits (54). In Kuwait, pharmacy students' preparedness for their smoking cessation role was significantly higher for nonsmoking pharmacy students compared to nonsmoking students in other disciplines (17).

In terms of objective three, students showed a serious lack of knowledge about existing national anti-smoking laws that: ban tobacco advertisement and promotion (11\%); ban smoking in public places (14\%); and ban selling cigarettes to minors (26\%). Such low knowledge of national tobacco legislations suggested that the authorized bodies might not have enforced those laws, the lack of non-compliance penalties, and the absence of educational brochures/awareness materials that address existing national anti-smoking laws. Thus there is a need to introduce the national anti-smoking laws in existing educational materials and to bridge the gap between the legal anti-smoking texts and practical 'on the ground' actions. Turkey passed an anti-tobacco law in 2008, yet five years later, law enforcement needed to be stronger (55). In Greece, the high percentages of health profession students who smoke and are exposed to SHS signified a lack of coordinated efforts for implementation and enforcement of anti-tobacco measures (54). In Lebanon, perceived barriers to implementation of non-smoking policy at university included the lack of compliance with and enforcement of the policy (56); and in India, stakeholders needed follow-up activities to enforce the anti-smoking laws and coordinated actions across the ministries/departments responsible for meeting the FCTC objectives and enforcing the legislations (57). In Gaza, while there are health promotion and educational signboards on the major streets, and at some schools and public institutions, still much effort is needed to raise awareness about the existing national anti-smoking laws and also in the enforcement of those laws (translation of the written words into actions). Therefore, in Palestine too, there is a crucial need for continuous capacity building training for stakeholders, strong government non-government partnerships, simple reporting mechanisms and early response systems to deal with violations (57).

In terms of religious issues, $61 \%$ of our participants reported that Islam prohibits smoking, while 34\% did not know what the Islamic stance was, and 6\% thought that the smoking is accepted in Islam. In Saudi Arabia, health and religious features were important motives for students not initiating smoking and reasons to quit smoking (21). We also agree with others that religious aspects are important for Muslims as Islam prohibits/discourages the habit $(21,58)$. Such insights are useful for intervention planning and design for these young adults.

As for objective four, although our sample's knowledge of legislation and existing anti-smoking laws was low, nevertheless knowledge levels were significantly higher among smokers than non-smokers for the laws that ban smoking in public places and selling cigarettes to minors. In agreement with a Moroccan study, a survey found low levels of information of current tobacco control legislation, where only $33.3 \%$ knew about the anti-smoking legislation, with more smokers than non-smokers (59). It is important to differentiate between knowledge of and support for the legislation; knowledge of the law might be higher in smokers, support for the law is higher in non smokers. In Turkey, support for the law was relatively lower among smokers than non-smokers (46).

For objective five, males were significantly associated with almost all categories of smoking (except cigarettes only). Compared to non-smokers, smokers of most categories were less likely to report that smoking causes harm to one's health and also less likely to try to prevent smoking near themselves. Conversely, for most smoking categories, smokers were more likely to accept that their first degree relative is a smoker. In agreement with a Cameroonian study (smoking was associated with male sex), as well as with a US study, small cigar users were more likely to be male, and current cigarette or hookah smokers also reported lower perceived harm of smoking $(60,61)$. College students who reported life-time hookah use, as compared to those who did not, perceived less associated harm, were more likely to use cigarettes in higher frequencies/quantities, and were at higher risk for tobacco use (62). In Cyprus, intention to quit was associated with belief that smoking is harmful to them (for males), and belief that 
smoking is harmful to others (for females) (43). Tobacco control programmes in Palestine should consider these correlates.

This study has limitations. The study was conducted on campus; those absent on the day might not have an opportunity to participate. Data were collected from 7 universities in Gaza (not the West Bank). Data were self-reported; under-reporting/social desirability bias cannot be ruled out, particularly for females. No objective/biochemical validation of smoking was undertaken, and the cross-sectional design does not allow inference of causal relationships. To minimize respondent burden, we did not assess parental education, socio-economic status, friends' smoking, or psychological factors that influence smoking. We did not differentiate between types of narghile tobacco and methods of narghile smoking. For those who smoked cigarettes and narghile, we did not assign their smoker status based on their major (primary) smoking pattern (mainly cigarettes - less narghile; or mainly narghile - less cigarettes). We tested only two rulings of the position of Islam on smoking which do not cover all the possibilities to judge action in Islam (actions in Islam can be judged as: obligatory, commendable, permitted, abhorrent, or not allowed). Future research should address these limitations.

\section{CONCLUSION}

Tobacco use is a global burden that requires actions at multiple levels. This study sheds light on the low levels of knowledge of the current tobacco control legislation (existing national anti-smoking laws in Palestine), and the lower levels of health knowledge among smokers when compared to non-smokers. There is an urgent need to implement actions that raise awareness toward smoking and its ill effects among students in Gaza as a first step towards facilitating behaviour change. In addition, a priority to be considered by national agencies and government departments is the establishing and equipping of smoking cessation centres across the Gaza Strip. Enforcing the existing anti-smoking laws in Palestine and raising awareness about these laws among the Palestinian university population is also required. Implementation of tobacco use prevention and intervention programmes for university students is warranted and research on the effectiveness of such initiatives is necessary.

\section{Acknowledgement}

The authors acknowledge the students and universities and colleges that participated in the study.

\section{Conflict of Interest}

None declared

\section{REFERENCES}

1. World Health Organization. WHO report on the global tobacco epidemic, 2011: warning about the dangers of tobacco. Geneva: WHO; 2011.

2. U.S. Department of Health and Human Services. The health consequences of involuntary exposure to tobacco smoke: a report of the surgeon general. Atlanta (GA): Centers for Disease Control and Prevention; 2006.

3. Mathers CD, Loncar D. Projections of global mortality and burden of disease from 2002 to 2030. PLoS Med. 2006 Nov;3(11):e442.
4. Wetter DW, Kenford SL, Welsch SK, Smith SS, Fouladi RT, Fiore MC, et al. Prevalence and predictors of transitions in smoking behavior among college students. Health Psychol. 2004 Mar;23(2):168-77.

5. Fikri M, Abi Saab BH. Global youth tobacco survey: United Arab Emirates Report 2002. Abu Dhabi (UEA): Ministry of Health; 2002.

6. Grunbaum JA, Kann L, Kinchen S, Ross J, Hawkins J, Lowry R, et al. Youth risk behavior surveillance - United States, 2003. MMWR Surveill Summ. 2004 May;53(2):1-96.

7. U.S. Department of Health and Human Services. How tobacco smoke causes disease: the biology and behavioral basis for smoking-attributable disease: a report of the Surgeon General. Atlanta (GA): Centers for Disease Control and Prevention; 2010.

8. World Health Organization. MPOWER: a policy package to reverse the tobacco epidemic. Geneva: WHO; 2008.

9. Jradi H, Wewers ME, Pirie PR, Binkley PF, Ferketich K. Cigarette and waterpipe smoking associated knowledge and behaviour among medical students in Lebanon. East Mediterr Health J. 2013 Oct;19(10):861-8.

10. Öztürk C, Bektaş M, Yilmaz E, Salman F, Şahin T, İlmek M, et al. Smoking status of Turkish nursing students and factors affecting their behavior. Pac J Cancer Prev. 2011;12(7):1687-92.

11. Ulus T, Yurtseven E, Donuk B. Prevalence of smoking and related risk factors among Physical Education and Sports School students at Istanbul University. Int J Environ Res Public Health. 2012 Mar;9(3):674-84.

12. Askarian M, Kouchak F, Youssef M, Romito LM. comparing tobacco use knowledge, attitudes and practices between engineering students at a public and Islamic Azad university in Shiraz, Iran 2011. Int J Prev Med. 2013 Oct;4(10):1154-61.

13. Sabahy AR, Divsalar K, Bahreinifar S, Marzban M, Nakhaee N. Waterpipe tobacco use among Iranian university students: correlates and perceived reasons for use. Int J Tuberc Lung Dis. 2011 Jun;15(6):844-7.

14. Maziak W, Fouad FM, Asfar T, Hammal F, Bachir EM, Rastam S, et al. Prevalence and characteristics of narghile smoking among university students in Syria. Int J Tuberc Lung Dis. 2004 Jul;8(7):882-9.

15. Al-Kubaisy W, Abdullah NN, Al-Nuaimy H, Halawany G, Kurdy S. Epidemiological study on tobacco smoking among university students in Damascus, Syrian Arab Republic. East Mediterr Health J. 2012 Jul;18(7):723-7.

16. Khabour OF, Alzoubi KH, Eissenberg T, Mehrotra P, Azab M, Carroll $\mathrm{MV}$, et al. Waterpipe tobacco and cigarette smoking among university students in Jordan. Int J Tuberc Lung Dis. 2012 Jul;16(7):986-92.

17. Waheedi M, Al-Tmimy AM, Enlund H. Preparedness for the smoking cessation role among health sciences students in Kuwait. Med Princ Pract. 2011;20(3):237-43.

18. Taha AZ, Sabra AA, Al-Mustafa ZZ, Al-Awami HR, Al-Khalaf MA, Al-Momen MM. Water pipe (shisha) smoking among male students of medical colleges in the eastern region of Saudi Arabia. Ann Saudi Med. 2010 May-Jun;30(3):222-6.

19. El Ansari W, Labeeb S, Kotb S, Yousafzai MT, El-Houfey A, Stock C. Correlates of smoking, quit attempts and attitudes towards total smoking bans at university: findings from eleven faculties in Egypt. Asian Pac J Cancer Prev. 2012;13(6):2547-56.

20. Abdulghani HM, Alrowais NA, Alhaqwi AI, Alrasheedi A, Al-Zahir M, Al-Madani A, et al. Cigarette smoking among female students in five medical and nonmedical colleges. Int J Gen Med. 2013 Aug 21;6:719-27.

21. Al-Kaabba AF, Saeed AA, Abdalla AM, Hassan HA, Mustafa AA. Prevalence and associated factors of cigarette smoking among medical students at King Fahad Medical City in Riyadh of Saudi Arabia. J Family Community Med. 2011 Jan;18(1):8-12.

22. Musmar SG. Smoking habits and attitudes among university students in Palestine: a cross-sectional study. East Mediterr Health J. 2012 May;18(5):454-60.

23. Gilpin EA, White VM, Pierce, JP. What fraction of young adults are at risk for future smoking, and who are they? Nicotine Tob Res. 2005 Oct; 7(5):747-59.

24. Al Sabbah H, Vereecken C, Abdeen Z, Kelly C, Ojala K, Németh A, et al. Weight control behaviors among overweight, normal weight and underweight adolescents in Palestine: findings from the national study of Palestinian schoolchildren (HBSC-WBG2004). Int J Eat Disord. 2010 May;43(4):326-36.

25. Palestinian National Authority Health Strategy 2011-2013: setting direction - getting results. Ramallah: Ministry of Health; 2010.

26. The Palestinian No Smoking law No 25. Palestine: Palestinian Authority; 28 March 2013.

27. Palestinian Central Bureau of Statistics [Internet]. Ramallah: PCBS; 2013 [cited 2013 Sep 3]. A Press Release on the Eve of the World Health 
Day. Available from: http://82.213.38.42/Portals/_pcbs/PressRelease/ HealthWDay2012E.pdf.

28. Palestinian Central Bureau of Statistics [Internet]. Ramallah: PCBS; 2013 [cited 2013 Sep 3]. On the Eve of International Youth Day 12/8/2013. Available from: http://www.pcbs.gov.ps/site/512/defaultaspx?tabID=5 12\&lang $=$ en\&ItemID $=866 \&$ mid $=3172 \&$ wversion=Staging.

29. Palestinian Central Bureau of Statistics. Palestinian Expenditure and Consumption Survey 2010. Ramallah: PCBS; 2011.

30. World Health Organization [Internet]. Cairo: WHO Regional Office for the Eastern Mediterranean; 2011 [cited 2013 Sep 3]. Occupied Palestinian Territory. World No Tobacco Day celebration 2011, 31 May 2011. Available from: http://www.emro.who.int/pse/palestine-news/world-notobacco-day-celebration-2011.html.

31. Center For Disease Control and Prevention [Internet]. Atlanta: CDC; 2011 [cited 2011 Aug 23]. Smoking \& Tobacco Use: Global Youth Tobacco Survey. Available from: http://www.cdc.gov/Tobacco/global/gtss/index. $\mathrm{htm}$.

32. Khader YS, Alsadi AA. Smoking habits among university students in Jordan: prevalence and associated factors. East Mediterr Health J. 2008 Jul-Aug;14(4):897-904.

33. Center For Disease Control and Prevention [Internet]. Atlanta: CDC; 2011 [cited 2011 Aug 23]. Smoking \& Tobacco Use: National Youth Tobacco Survey (NYTS). Available from: http://www.cdc.gov/tobacco/ data_statistics/surveys/nyts/.

34. Almerie MQ, Matar HE, Salam M, Morad A, Abdulaal M, Koudsi A, et al. Cigarettes \& waterpipe smoking among medical students in Syria: a cross-sectional study. Int J Tuberc Lung Dis. 2008 Sep;12(9):1085-91.

35. Jarallah JS, al-Rubeaan KA, al-Nuaim AR, al-Ruhaily AA, Kalantan KA. Prevalence and determinants of smoking in three regions of Saudi Arabia. Tob Control. 1999;8(1):53-6.

36. Mubeen SM, Morrow M, Barraclough S. Medical students' perspectives on gender and smoking: a mixed methodology investigation in Karachi, Pakistan. J Pak Med Assoc. 2011 Aug;61(8):773-8.

37. Fernández García D, Martín Sánchez V, Vázquez Casares AM, Liébana Presa C, Fernández Martínez ME, De Luis González JM. Tobacco use amongst nursing and physiotherapy students: a cross sectional questionnaire survey. Int J Nurs Stud. 2007 Jul;44(5):780-5.

38. Warren CW, Sinha DN, Lee J, Lea V, Jones NR. Tobacco use, exposure to secondhand smoke, and training on cessation counseling among nursing students: cross-country data from the Global Health Professions Student Survey (GHPSS), 2005-2009. Int J Environ Res Public Health. 2009 Oct;6(10):2534-49.

39. Fielder RL, Carey KB, Carey MP. Hookah, cigarette, and marijuana use: a prospective study of smoking behaviors among first-year college women. Addict Behav. 2013 Nov;38(11):2729-35.

40. Chen X, Jacques-Tiura AJ. Smoking initiation associated with specific periods in the life course from birth to young adulthood: data from the National Longitudinal Survey of Youth 1997. Am J Public Health. 2014 Feb;104(2):e119-26.

41. Piasecki TM, Richardson AE, Smith SM. Self-monitored motives for smoking among college students. Psychol Addict Behav. 2007 Sep;21(3):328-37.

42. Labib N, Radwan G, Mikhail N, Mohamed MK, Setouhy ME, Loffredo $\mathrm{C}$, et al. Comparison of cigarette and water pipe smoking among female university students in Egypt. Nicotine Tob Res. 2007 May;9(5):591-6.

43. Savvides EC, Christophi CA, Paisi M, Pampaka D, Kinnunen T, Connolly GN. Factors associated with intent to quit tobacco use in Cyprus adolescents. Prev Med. 2014 Mar;60:83-7.

44. Centers for Disease Control and Prevention (CDC). State cigarette excise taxes - United States, 2009. MMWR Morb Mortal Wkly Rep. 2010 Apr 9;59(13):385-8

45. Hu TW, Mao Z, Shi J, Chen W. The role of taxation in tobacco control and its potential economic impact in China. Tob Control. $2010 \mathrm{Feb} ; 19(1): 58$ 64.
46. Cakir B, Buzgan T, Com S, Irmak H, Aydin E, Arpad C. Public awareness of and support for smoke-free legislation in Turkey: a national survey using the lot quality sampling technique. East Mediterr Health J. 2013 Feb;19(2):141-50.

47. Maziak W. The waterpipe: time for action. Addiction 2008 Nov;103(11):1763-7.

48. Al-Naggar RA, Saghir FS. Water pipe (shisha) smoking and associated factors among Malaysian university students. Asian Pac J Cancer Prev. 2011;12(11):3041-7.

49. Chaaya M. A comparative study of smoking behavior among university students in Lebanon one decade apart (1998-2007). In: 14th World Conference on Tobacco or Health; 2009 Mar 8-12; Mumbai, India.

50. Dar-Odeh NS, Bakri FG, Al-Omiri MK, Al-Mashni HM, Eimar HA, Khraisat AS, et al. Narghile (water pipe) smoking among university students in Jordan: prevalence, pattern and beliefs. Harm Reduct J. 2010 May 24;7:10.

51. Knishkowy B, Amitai Y. Water-pipe (narghile) smoking: an emerging health risk behavior. Pediatrics. 2005 Jul;116(1):e113-9.

52. Klassen BJ, Smith KZ, Grekin ER. Differential relationships between religiosity, cigarette smoking, and waterpipe use: implications for college student health. J Am Coll Health. 2013;61(7):381-5.

53. Nakkash R, Khalil J. Health warning labelling practices on narghile (shisha, hookah) waterpipe tobacco products and related accessories. Tob Control. 2010 Jun;19(3):235-9.

54. Barbouni A, Hadjichristodoulou C, Merakou K, Antoniadou E, Kourea $\mathrm{K}$, Miloni E, et al. Tobacco use, exposure to secondhand smoke, and cessation counseling among health professions students: Greek data from the global health professions student Survey (GHPSS). Int J Environ Res Public Health. 2012 Jan;9(1):331-42.

55. Inandi T, Caman OK, Aydin N, Onal AE, Kaypmaz A, Turhan E, et al. Global Health Professions Student Survey-Turkey: second-hand smoke exposure and opinions of medical students on anti-tobacco law. Cent Eur J Public Health. 2013 Sep;21(3):134-9.

56. Chaaya M, Alameddine M, Nakkash R, Afifi RA, Khalil J, Nahhas G. Students' attitude and smoking behaviour following the implementation of a university smoke-free policy: a cross-sectional study. BMJ Open. 2013 Apr 11;3(4):pii:e002100.

57. Panda B, Rout A, Pati S, Chauhan AS, Tripathy A, Shrivastava R, et al. Tobacco control law enforcement and compliance in Odisha, India implications for tobacco control policy and practice. Asian Pac J Cancer Prev. 2012;13(9):4631-7.

58. Al-Turki YA. Smoking habits among medical students in Central Saudi Arabia. Saudi Med J. 2006 May;27(5):700-3.

59. Tachfouti N, El RK, Berraho M, Benjelloun MC, Slama K, Nejjari C. Knowledge and attitude about antismoking legislation in Morocco according to smoking status. East Mediterr Health J. 2011 Apr;17(4):297-302.

60. Mbatchou Ngahane BH, Luma H, Mapoure YN, Fotso ZM, Afane Ze E. Correlates of cigarette smoking among university students in Cameroon. Int J Tuberc Lung Dis. 2013 Feb;17(2):270-4.

61. Sterling K, Berg CJ, Thomas AN, Glantz SA, Ahluwalia JS. Factors associated with small cigar use among college students. Am J Health Behav. 2013 May;37(3):325-33.

62. Heinz AJ, Giedgowd GE, Crane NA, Veilleux JC, Conrad M, Braun AR, et al. A comprehensive examination of hookah smoking in college students: use patterns and contexts, social norms and attitudes, harm perception, psychological correlates and co-occurring substance use. Addict Behav. 2013 Nov;38(11):2751-60. 